\title{
Mechanical properties of an extruded wood plastic composite
}

\author{
Françoise Hugot ${ }^{1, a}$ And Gilles Cazaurang ${ }^{2}$ \\ 1 Université de Limoges, ENSIL, Parc d'Ester, 16 rue Atlantis, 87068 Limoges, France \\ 2 Université Bordeaux I, IUT, EA LGM²B, 15 rue Naudet, CS 10207, 33175 Gradignan, France
}

Received 3 October 2007, Accepted 3 December 2009

\begin{abstract}
The focus of this study has been to fully describe the mechanical properties and behaviour of an extruded Wood Plastic Composite product. The use of plasturgy technologies for the elaboration of lignocellulose reinforced composites raises fundamental questions about the behaviour of these materials. Mechanical properties of a composite depend generally on fibre content, fibre/matrix interface link or added coupling agents. Processes play an important role on the reinforcement distribution in the matrix. The main purpose of this paper is to describe mechanical behaviour of WPC composites which are manufactured using an extrusion process. So, complete set of experiments has been realised: tensile, compressive, bending and shear tests. Longitudinal direction refers to extrusion process directional flow and transverse direction specimens have been tested. Mechanical performances of Wood Plastic Composites depend also on the link of fibre/matrix interface, fracture surface has been analysed using an optical microscope.
\end{abstract}

Key words: Polymer matrix / composites / WPC / HDPE / wood fibre / mechanical properties

Résumé - Performances mécaniques d'un composite bois/polymère obtenu par le procédé d'extrusion. Les matériaux composites à base de bois possèdent un potentiel de développement technique important et un avantage concurrentiel sur les bases de critères environnementaux. Le comportement de composites à base de bois est très complexe car il dépend de plusieurs paramètres. En effet la distribution spatiale des fibres et l'absence ou non d'agent de couplage sont des facteurs pouvant influencer la réponse de ces composites soumis à une sollicitation extérieure. L'objectif de cette étude est donc de déterminer le comportement mécanique d'un composite dont la matrice polymère est renforcée par des éléments discontinus (fibres de bois). Dans des conditions de température et d'humidité relatives du laboratoire, l'étude du comportement en traction, compression, flexion et cisaillement de composites bois/polymères extrudés a été réalisée dans le sens longitudinal et perpendiculairement au sens de l'extrusion. Les propriétés mécaniques de ces composites étant aussi tributaires de la qualité de l'interface fibre/matrice, l'interface a été visualisée à l'aide un microscope optique.

Mots clés : Matrice polymère / composites / WPC / HDPE / fibres de bois / propriétés mécaniques

\section{Introduction}

In recent years, Wood Plastic Composites (WPC) have attracted great interest in composite science and commercial developments. In North America WPC decking represent $65 \%$ of WPC market with $15 \%$ share of global decking market $[1,2]$. The European WPC market is small compared to the North American one but growing despite a lack of commercial leadership [3]. The replacement of petrol based products by renewable materials is an economic and environmental issue. Wood fibres have the advantage to be recyclable and abundant.

\footnotetext{
${ }^{a}$ Corresponding author: hugot@ensil.unilim.fr
}

Studies deal with WPC properties: different attempts were made with various raw materials (natural fibres and virgin or recycled polymers) and different morphologies [4-9]. Problematics like interfacial adhesion were outlined and solutions (coupling agent, surface treatments) are discussed comparing mechanical properties of WPC formulations [10-12]. Also, some works show the nonlinear behaviour of WPC material [13-15].

The main purpose of this paper is to describe the mechanical properties of a WPC composite. Experimental tests (tensile, compressive, three points bending and shear tests) of a WPC composite which are manufactured using an extrusion process were carried out in order to determine mechanical properties. Observations of WPC 


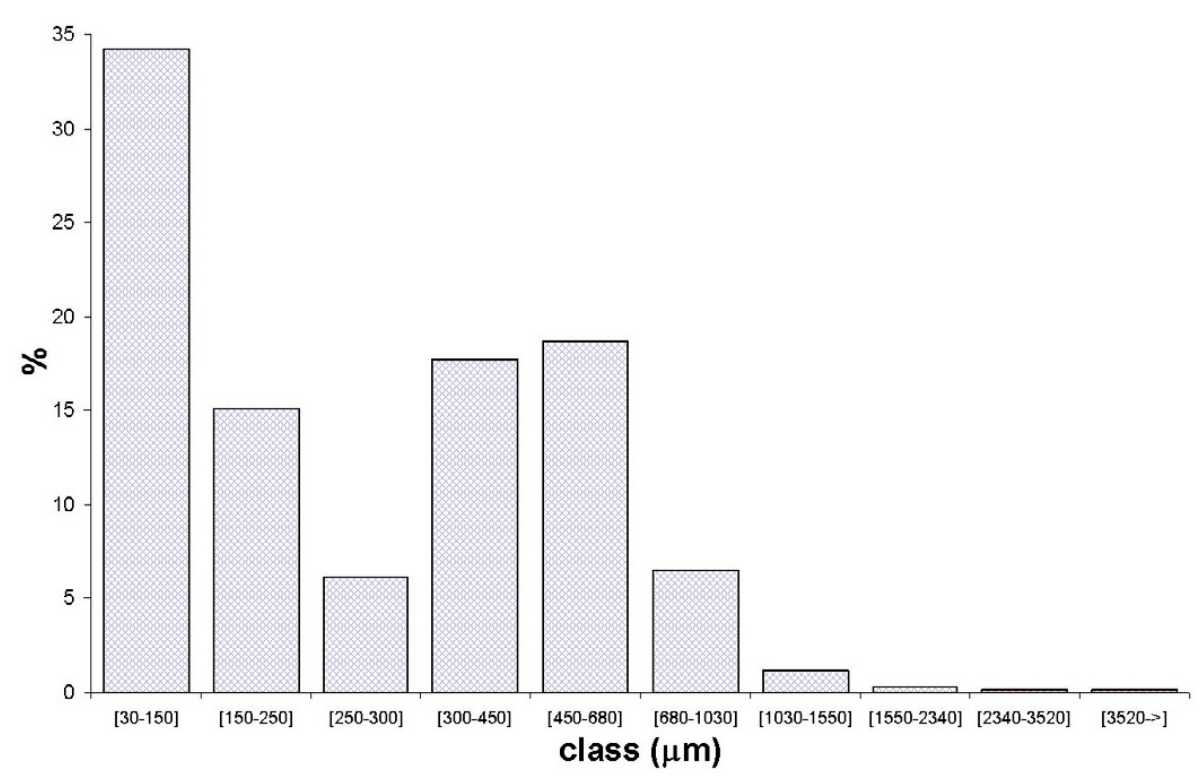

Fig. 1. Wood fibres morphological characteristics.

Table 1. Raw material properties.

\begin{tabular}{l|l|cccccccc}
\hline \multicolumn{2}{c|}{ Properties $(\mathrm{MPa})$} & \multicolumn{2}{c}{ Tension } & \multicolumn{2}{c}{ Compression } & \multicolumn{2}{c}{ Bending } & \multicolumn{2}{c}{ Shear } \\
& & Long. & Trans. & Long. & Trans. & Long. & Trans. & Long. & Trans. \\
\hline Pine & MOE & 12000 & 800 & 12000 & 800 & 11200 & 800 & 750 & 80 \\
Wood $^{1}$ & $\sigma_{\max }$ & 51 & 3.2 & 25 & 25 & 20 & - & 6.5 & - \\
\hline \multirow{2}{*}{$\mathrm{HDPE}^{2}$} & MOE & 1250 & 1250 & 1250 & 1250 & 1250 & 1250 & 250 & 250 \\
& $\sigma_{\max }$ & 25 & 25 & 20 & 20 & 20 & - & - & - \\
\hline
\end{tabular}

${ }^{1}$ Data from literature [16], ${ }^{2}$ experimental data from HDPE compression moulding tests, MOE modulus of elasticity, $\sigma_{\max }$ : maximum stress.

composite tensile failure with an optical microscope has been realized to characterize the fibre/matrix bonding quality.

\section{Materials}

A commercial WPC dedicated to decking applications, is used for this study. This product is made by twin screw extrusion processing of $60 \%$ wood, $30 \%$ HDPE (High Density Polyethylene) polymer and $10 \%$ of additives. HDPE polymer granulates are from ATOFINA and additives contain coupling and dispersive agents, lubricant, stabilisers and talc.

Wood is softwood sawdust with morphological characteristics described in Figure 1. Optical scanning device of fibre is used to determine size distribution in frequency of wood fibres. MorFi LB01 system from Techpap allowed these morphological characteristic measurements of wood elements. Frequency distribution does not take into account the very small elements (length $<30 \mu \mathrm{m}$ ), called fines, which represent about $90 \%$ in total length and $20 \%$ of the total surface of all elements analysed.

HDPE polymer specimens are produced, in laboratory conditions, by compression moulding at $180{ }^{\circ} \mathrm{C}$ in order to have a set of mechanical properties.
All properties of raw material are summarized in Table 1.

\section{Experimental methods}

Based on standard guide for evaluating mechanical properties of WPC products, different appropriated test methods are chosen for each property. Mechanical characterisation was carried out onto a set of 20 specimens for each test using a universal testing machine device (ADAMEL, MTS).

\subsection{Conditioning}

Prior to testing, all specimens were conditioned to a temperature of $20{ }^{\circ} \mathrm{C} \pm 2$ and a relative humidity of $65 \% \pm 3$ for several weeks in order to reach equilibrium state.

\subsection{Tensile and three points bending tests}

Tensile and three points bending properties are tested according to standard dedicated for plastics and reinforced plastics composites, NF EN ISO 527-1-4 and 


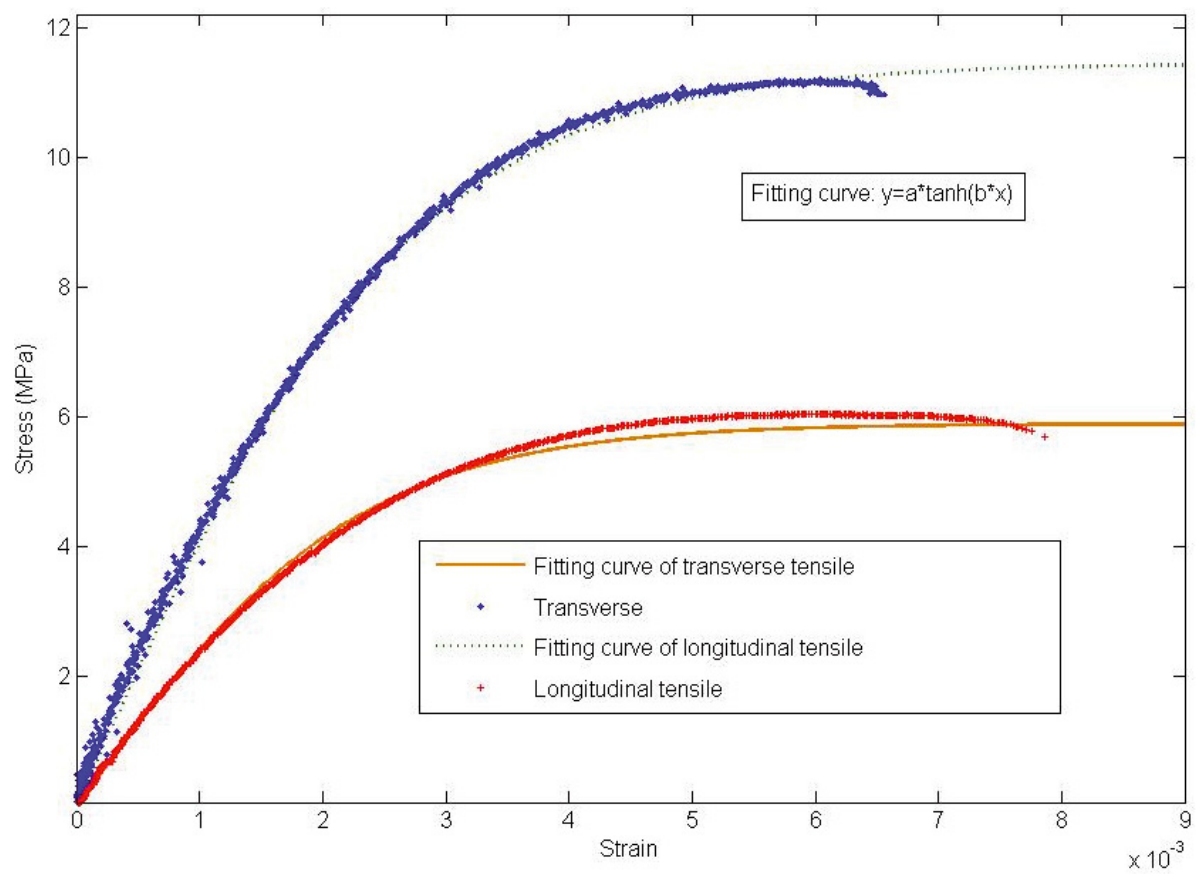

Fig. 2. Experimental and fitted tension stress strain curves.

NF EN ISO 178-1 respectively. Thickness of tensile "rectangular dog bone" sample is $3 \mathrm{~mm}$. Bending specimen size is $4 \times 10 \times 67 \mathrm{~mm}^{3}$. Tensile and three points bending speeds are $0.5 \mathrm{~mm} \cdot \mathrm{min}^{-1}$ and $1 \mathrm{~mm} \cdot \mathrm{min}^{-1}$ respectively.

\subsection{Compressive and shear tests}

Compressive and shear tests are carried out tested according to standard dedicated for wood specimens ASTM D143. Compressive specimen size is $20 \times 20 \times 60 \mathrm{~mm}^{3}$. Shear specimen size is $25 \times 25 \times 35 \mathrm{~mm}^{3}$ with a notched corner of $10 \times 10 \mathrm{~mm}^{3}$. Compressive and shear test speeds are $0.3 \mathrm{~mm} \cdot \mathrm{min}^{-1}$ and $1 \mathrm{~mm} \cdot \mathrm{min}^{-1}$ respectively.

\subsection{Fitting curve method}

The Curve Fitting Toolbox of MATLAB ${ }^{\circledR}$ software is used to create fitting curves of the stress-strain behaviour of our material. The nonlinear relationship is described by Zawlocki [17] using a hyperbolic tangent function (Eq. (1)).

$$
\sigma=a \tanh (b \varepsilon)
$$

$\sigma, \varepsilon$ : respectively stress and strain; $a, b$ : fitting parameters estimated by statistical analysis.

\section{Experimental results}

Longitudinal direction (Long.) refers to extrusion process directional flow (wood fibre orientation) while transverse direction (Trans.) takes into account the transverse isotropic behaviour of these materials. The maximum stress $\left(\sigma_{\max }\right)$ is selected in order to compare different tests.

\subsection{WPC behaviour}

WPC stress strain curves present a global non linear behaviour which is closer to thermoplastic behaviour than usual wood brittle linear one. Indeed, WPC curves exhibit a constant accumulation of residual strain which can be well described using a hyperbolic tangent function as suggested by Zawlocki [17]. Tensile and three points bending curves (Figs. 2 and 3 respectively) do not exhibit a distinct point suitable to determine yield point.

Reinforcement created by fibre orientation due to the extrusion process induces a higher longitudinal stress response (up to two times than transverse) at a same strain for both tensile and three points bending curves. Hyperbolic tangent functions show $R^{2}$ above 0.99 for three points bending fitting curves and above 0.85 for tensile fitting curves.

Tensile and three points bending wood, plastic and WPC stress strain relationships are reported in Figure 4. Wood behaviour presents a higher tensile than compressive resistance. Tensile failure is brittle whereas compressive failure tends to be more ductile. HDPE polymer tested shows a higher tensile than compressive strength.

Surprisingly, Wood Plastic Composites behave differently of its components (Fig. 4c). Compressive strength is higher than tensile one. The contrary effect emphasis a lack of reinforcement expected from wood fibres. It seems that in tension, wood fibres behave like an inclusion, whereas in compression, it acts like encapsulated 


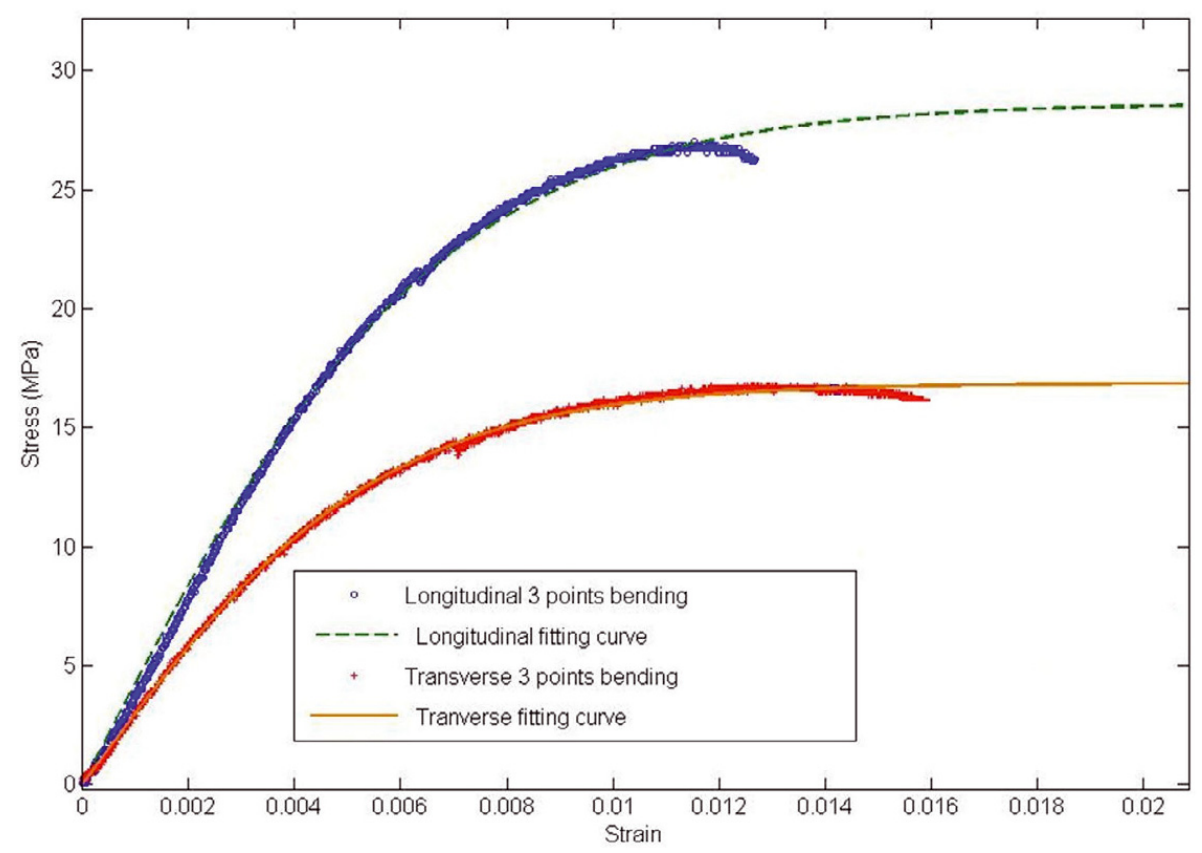

Fig. 3. Experimental and fitted bending stress strain curves.

Table 2. Mechanical properties of WPC product.

\begin{tabular}{l|cccccccc}
\hline $\begin{array}{l}\text { WPC } \\
\text { Properties } \\
(\mathrm{MPa})\end{array}$ & Long. & Trans. & Long. & Trans. & Long. & Trans. & Long. & Trans. \\
\hline MOE $_{\text {norm }}$ & 3000 & 1500 & 3700 & 1980 & 4100 & 2660 & 240 & 220 \\
& $(340)$ & $(150)$ & $(215)$ & $(150)$ & $(235)$ & $(190)$ & $(35)$ & $(25)$ \\
MOE $_{\text {tangent }}$ & 4700 & 2540 & - & - & 4300 & 2800 & - & - \\
& $(550)$ & $(460)$ & & & $(470)$ & $(185)$ & & \\
$\sigma_{\max }$ & 11.6 & 5.3 & 28.1 & 25.4 & 26.1 & 16.7 & 8.1 & 7.1 \\
& $(1.0)$ & $(0.5)$ & $(0.7)$ & $(0.8)$ & $(1.0)$ & $(0.5)$ & $(0.4)$ & $(0.3)$ \\
\hline
\end{tabular}

$\mathrm{MOE}_{\text {tangent }}$ : modulus of elasticity taken as the tangent at $x=0$ of the hyperbolic tangential function fitted onto experimental values for each sample test. ( ): standard deviation.

filler. Despite low interfacial bonding, a mechanical entanglement between wood fibres and HDPE polymer occurs to allow taking benefit during compressive test. In fact, fines elements without aspect ratio effect should increase WPC compressive properties.

\subsection{Mechanical properties}

Due to the global non linear behaviour of WPC product, mechanical properties such as MOE are difficult to obtain. Indeed standard guide recommendations are often not suitable for this composite. Therefore, we decided to evaluate the MOE using specification for reinforced plastic standard $\left(\mathrm{MOE}_{\text {norm }}\right.$ taken between $5 \times 10^{-4}$ and $2.5 \times 10^{-3}$ of strain) and to define a tangent modulus of elasticity based on the first derivate of hyperbolic tangent function $\left(\mathrm{MOE}_{\text {tangent }}\right)$. The latter one is the more appropriate to calculate tensile elastic modulus. Difference between $\mathrm{MOE}_{\text {norm }}$ and $\mathrm{MOE}_{\text {tangent }}$ confirms an underestimation of MOE standard method due to the non-linear behaviour. Results are summarized in Table 2 .

Tensile and three points bending values of transverse MOE confirm the anisotropic behaviour of an extruded Wood Plastic Composite.

Tensile and three points bending maximal stresses $\left(\sigma_{\max }\right)$ are up to two times smaller than longitudinal values. Compressive and shear maximal stresses are almost unaffected by directional consideration.

Tensile maximal stress is far lower for Wood Plastic Ccomposite $\left(\sigma_{\mathrm{tl}}=11.6 \mathrm{MPa}\right)$ than $\operatorname{HDPE}\left(\sigma_{\mathrm{tl}}=25 \mathrm{MPa}\right)$ and wood $\left(\sigma_{\mathrm{tl}}=50 \mathrm{MPa}\right)$ which leads to conclude that somehow wood elements act more like a filler even like an inclusion than a real reinforcement. For instance, interfacial adhesion plays a main role in load transfer from the matrix to the fibre. Compressive and three points bending properties are less dependent on adhesion quality than tensile ones. 


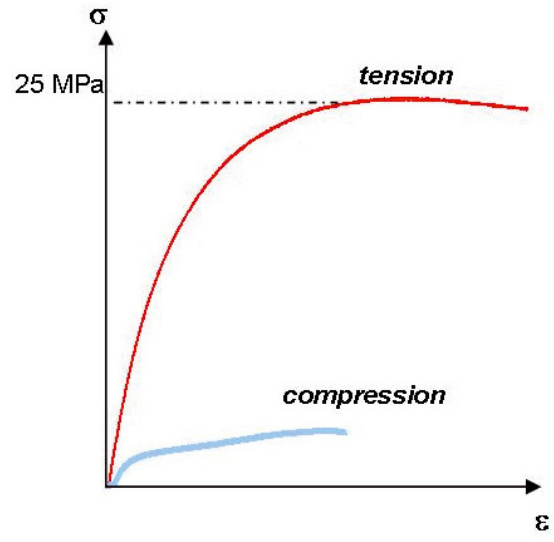

a. HDPE

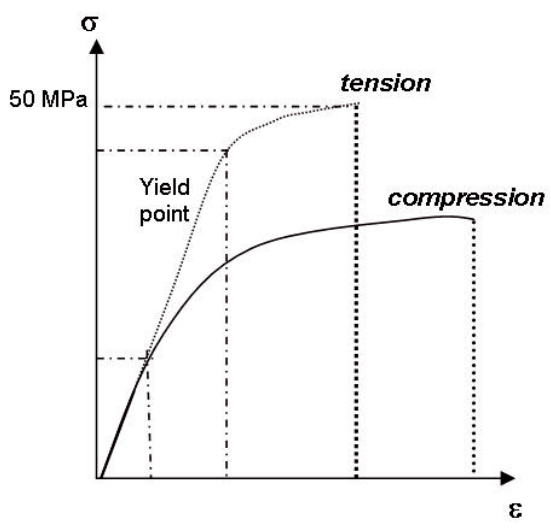

b. Wood

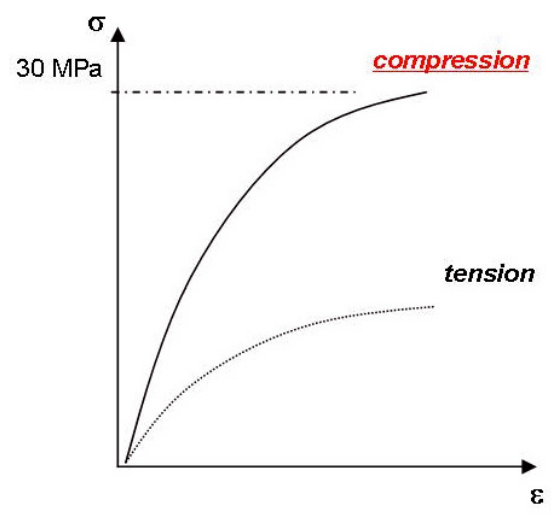

\section{c. WPC}

Fig. 4. Comparison of wood, HDPE and WPC mechanical behaviour in tension and compression.

\subsection{Fracture appearance}

Material composite failure modes can be initiated by fibre breakage, fibre/matrix interfacial debonding, fibre pull-out or matrix plastic deformation and cracking. Mechanical function of reinforced composite can only be efficient if stresses are transferred from the matrix to the

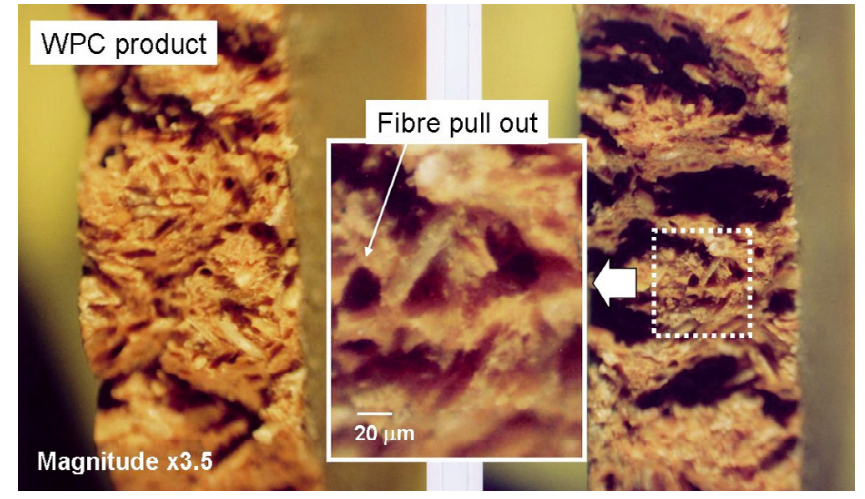

Fig. 5. Failure appearance of WPC.

fibre. Load transfer depends on the mechanical response of the interface zone between the fibre and the matrix.

Observations of WPC tensile failure with an optical microscope (Fig. 5), present an evidence of fibre pull out which is characteristic of poor interfacial adhesion. Same trends of failure behaviour are observed for different applied loads. Weak interfacial bonding is a well known problem of WPC due to incompatibility of both components. Coupling agent incorporated in this commercial product may not be efficient enough and additional improvements should be done to link wood fibre to thermoplastic in order to prevent the fibre pull out leading to a better load transfer. Interfacial bonding quality is a key point of mechanical performance for Wood Plastic Composite.

\section{Conclusion}

The focus of this study has been to predict an extruded Wood Plastic Composite behaviour. Experiment tests have been realised to characterize its mechanical properties: tensile, compressive, three points bending and shear tests. Extrusion process creates anisotropic behaviour and gives higher longitudinal properties. Evidence of the global non linear behaviour of this Wood Plastic Composite was showed.

On one hand, good compressive and three points bending performances were observed in agreement with application requirements for this decking main product. On the other hand lower tensile performance and failure appearances revealed a lack of interfacial bonding between wood fibre and matrix despite the presence of a coupling agent in the composite formulation.

Problematic like interfacial adhesion is fundamental: indeed, fibre pull out observations indicate a lack of adhesion between wood fibres and HDPE polymer although the presence of a coupling agent. Mechanical performance of fibre reinforced composites strongly depends on fibre orientation and interfacial quality bounding.

Further WPC formulations [18] have been studied to describe the physical and mechanical properties of WPC composites which are manufactured using extrusion or injection processes. 
Acknowledgements. Authors thank B. Solbes (Université Bordeaux 1, US2B) for his technical assistance.

\section{References}

[1] C.M. Clemons, Wood-Plastic Composites in the United States. The interfacing of two industries, Forest Prod. J. 52 (2002) 10-18

[2] J.A. Youngquist, R.M. Rowell, Opportunities for combining wood with nonwood materials, Proc. 23rd Washington State University, Int. Particle/Composite Mater., Washi lastics Additives \& Compounding, 1989

[3] M. Holmes, Wood-plastic composites: current trends in materials and processing, Plastics Additives \& Compounding, 2005

[4] N.M. Stark, A.R. Sanadi, Effects of fiber type on the properties of wood-plastic composites, Progress in woodfibre-plastic composites conference, Toronto, Ontario Canada, Materials and Manufacturing Ontario, 2000

[5] A.D. Beshay, B.V. Kotka, C. Daneault, Use of wood fibers in thermoplastic composites II: polyethylene, Polym. Compos. 6 (1985) 261-271

[6] K. Yam, V. Kalyankai, S. Selke, C. Lai, Mechanical properties of wood fiber/recycled HDPE composites, ANTEC (1998) 1809-1811

[7] B.V. Kotka, C. Daneault, A.D. Beshay, Use of grafted aspen fibers in thermoplastic composites IV: Effects of extreme conditions on mechanical properties of polyethylene composites, Polym. Compos. 7 (1986) 337-348

[8] A.M. Krzysik, J.A. Youngquist, G.E. Myers, I.S. Chahyadi, P.C. Kolosick, Wood-polymer bonding in extruded and nonwoven web composites panels, Proc. Of Wood Adhesives symposium 1990, Madison, USA, Forest Products Laboratory, 1991
[9] Y. Li, Y.W. Mai, L. Ye, Sisal fibre and its composites: A review of recent developments, Compos. Sci. Tech. 60 (2000) 2037-2055

[10] M. Takatani, H. Ito, S. Ohsugi, T. Kitayama, M. Saegusa, S. Kawai, T. Okamoto, Effect of lignocellulosic materials on the properties of thermoplastic polymer/wood composites, Holzforschung 54 (2000) 197-200

[11] S.M. Lai, F.C. Yeh, Y. Wang, H.C. Chan, H.F. Shen, Comparative study of maleated polyolefins as compatibilizers for polyethylene/wood flour composites, J. App. Polym. Sci. 87 (2003) 487-496

[12] A.K. Bledzki, J. Gassan, Composites reinforced with cellulose based fibres, Prog. Polym. Sci. 24 (1999) 221-274

[13] J.Z. Lu, Q. Wu, H.S. McNabb, Chemical coupling in wood fiber and polymer composites: A review of coupling agents and treatments, Wood Fib. Sci. 32 (2000) 88-104

[14] G. Lu, HDPE wood-plastic composite material model subject to damage, Master of Sciences in Civil Engineering, Washington State University, Department of Civil and Environmental Engineering, 2002

[15] F. Hugot, G. Cazaurang, Macroscopic properties of an extruded wood plastic composite: analytical modelling, Journal of wood chemistry and technology 28 (2008) 283295

[16] D. Guitard, Mécanique du matériau bois et des composites, Edition Cepadues, France, 1987

[17] M.M. Zawlocki, Characterization of wood-plastic composites by dissipated energy, Master of Sciences in Civil Engineering, Washington State University, Department of Civil and Environmental Engineering, 2003

[18] F. Hugot, F. Michaud, G. Cazaurang, Interface behaviour of moulded natural fibre composite, Proceeding International Conference on Recent Advances in Composites Material, ICRACM, Allied Publishers PVT. LTD, 2007, pp. 361-368 